\title{
ARTE Y OBRA DE LOS HOMBRES PRIMITIVOS EN EL ALTIPLANO. DESCRIPCIÓN DE LAS MANIFESTACIONES PICTOGRÁFICAS DE OQHORUNI EN LA COMUNIDAD DE ISIVILLA EN PUNO
}

Art and work of the primitive men in the Altiplano. Description of the pictographic manifestations of Oqhoruni in the community of Isivilla in Puno

\author{
Rudy Oswaldo Dávila-Quispe ${ }^{1}$ \\ UNIVERSIDAD NACIONAL DEL ALTIPLANO \\ PERÚ \\ 70376108@cepreuna.edu.pe \\ https://orcid.org/oooo-0002-2208-6234
}

DOI: https://doi.org/10.35622/j.rr.2021.06.004

Recibido: 30-II-2021 / Aceptado: 22-X-2021 / Actualizado: 01-XI-2021

\section{Resumen}

Desde un modelo de estudio cualitativo, de observación y de análisis documental, se busca describir las figuras iconográficas de las manifestaciones pictográficas de Oqhoruni de la comunidad de Isivilla del distrito de Corani-Carabaya en Puno. Los resultados desprenden que la descripción de dichas expresiones pictográficas a partir de algunas escenas como figuras antropomorfas, zoomorfas y geométricas, resaltan en su mayoría fuertes escenas de caza, el chaco y el caicu. En ese impar, sobre todo llama la atención de figuras geométricas, líneas paralelas de forma vertical y de pintados a colores de rojo oscuro, anaranjado, amarillo y blanco. Dentro de esas manifestaciones, puede concluirse que no cabe duda que, el arte y la obra de los hombres primitivos en el altiplano no solo han reflejado y dejado sobre las superficies rocosas actividades reales que los rodeaba en el medio donde vivían hace miles de años atrás. Sino que, además, se ve a lo lejos una fuerte insistencia de quedar inmortalizados en los encantamientos de Oqhoruni.

\footnotetext{
${ }^{1}$ Licenciado en Ciencias de la Educación, Maestrando en Didáctica de las Ciencias Sociales en la Escuela de Posgrado de la Universidad Nacional del Altiplano de Puno [UNAP].
} 
ARTE Y OBRA DE LOS HOMBRES PRIMITIVOS EN EL ALTIPLANO. DESCRIPCIÓN DE LAS MANIFESTACIONES PICTOGRÁFICAS DE OQHORUNI EN LA COMUNIDAD DE ISIVILLA EN PUNO ISSN: 2710-0499 ISSN-L: 2710-0480

Palabras Clave: Comunidad, descripción, histórico Isivilla, manifestación pictográfica.

\section{Abstract}

From a qualitative study model, observation and documentary analysis, the aim is to describe the iconographic figures of the pictographic manifestations of Oqhoruni in the Isivilla community of the Corani-Carabaya district in Puno. The results show that the description of said pictographic expressions from some scenes such as anthropomorphic, zoomorphic and geometric figures, mostly highlight strong hunting scenes, the chaco and the caicu. In that odd one, it especially draws the attention of geometric figures, vertical parallel lines and painted in colors of dark red, orange, yellow and white. Within these manifestations, it can be concluded that there is no doubt that the art and work of primitive men in the highlands have not only reflected and left on the rocky surfaces real activities that surrounded them in the environment where they lived thousands of years ago. But in addition, a strong insistence to be immortalized in the enchantments of Oqhoruni is seen in the distance.

Keyword: Community, description, historical Isivilla, pictographic manifestation.

\section{INTRODUCCIÓN}

En el conteniente americano la información sobre los más antiguos pobladores de los andes es escasa y fragmentaria. No cabe duda de que llegaron durante el pleistoceno, pues hay evidencias de la coexistencia de los seres humanos con los animales de ese periodo, hoy extintos. Las pruebas en edad de los hallazgos más antiguos son insuficientes y no satisfacen del mismo modo las expectativas de todos los prehistoriadores (Lumbreras, 1969). De eso, en las primeras referencias del arte rupestre en el Perú la más conocida y difundida es la de Toquepala que se encuentra en el departamento de Tacna que fue descubierta por Miomir Bojovich (1922-2013) en el año de 1960, porque tiene una datación de aproximadamente 9580 años a. C. lo que demuestra que es contemporánea a Lauricocha.

Las pinturas rupestres de estilos y épocas son diversas en la mayoría de los departamentos peruanos. Las más antiguas pinturas conocidas en el territorio, y que gozan de una situación cronológica más o menos establecida, pertenecen a la tradición andina. Cuevas con figuraciones características de este estilo naturalista se encuentran en los departamentos de Moquegua, Tacna, Puno y Arequipa. En la mayoría de los casos, se ubican en zonas de acceso difícil, en las partes medias y altas de la cordillera (2700 msnm. para Toquepala, $3800 \mathrm{msnm}$. para Pizacoma, y $4213 \mathrm{msnm}$. para Chillicua). Según Yaresi (2017), en la región de Puno existe una amplia distribución de sitios con arte rupestre; que demuestra la existencia de los primeros hombres en el Altiplano, específicamente en la provincia de Carabaya en los distritos de Macusani, Ituata, Coasa y Corani. Así, por ejemplo, la presencia de las manifestaciones pictográficas en los abrigos rocosos de Oqhoruni localizado en la comunidad de Isivilla del distrito de Corani-Carabaya en Puno, son una evidente e incuestionable expresión.

Revista Revoluciones -38- Vol. 3, No 6 (2021), pp. 37-52

Esta obra está bajo una licencia internacional Creative Commons Atribución 4.0. 
No obstante, su poca importancia es clara, pues la falta de fuentes bibliográficas sobre las manifestaciones rupestres de aquellas zonas alejadas en la región, son muestra no solo de la escaza información, sino también, del poco afán de descubrir el encantamiento de Oqhoruni. De manera que, el interés de la presente investigación es describir las distintas manifestaciones pictográficas, las escenas de las figuras icónicas y de esa manera conocer las actividades mitológicas; sociales y culturales del que se rodeaban los primeros habitantes de la comunidad de Isivilla.

\section{METODOLOGÍA}

El altiplano sur andino es el escenario donde se tuvo la presencia hace aproximadamente 10,000 a.C., cuando los primeros recolectores y cazadores buscaban sobrevivir en esta basta planicie altiplánica, buscando como viviendas natrales los abrigos rocosos en las diferentes latitudes. En la datación de RC-14 (10,000-7,000 a.C.) el altiplano estaba habitada por cazadores de fauna terrestre, es decir, de animales que hoy en día existen en el altiplano puneño, especialmente los cérvidos y los camélidos. Entre estos cazadores se encuentran los primeros ocupantes de los abrigos rocosos de Pizacoma, Mazo cruz, Puno, Lampa, Azángaro, Zepita y Macusani-Corani, otros a una altitud aproximadamente a más de 4,000 $\mathrm{msnm}$. (Martínez \& Botiva, 2004). De igual forma, Hostnig (2007) y Ramos (2002) realizaron estudios sitios donde se exhiben las manifestaciones rupestres, encontrando importantes abrigos rocosos y cuevas en donde se manifiestan las artes rupestres. El arqueólogo Ramos señala en su resultado de su trabajo de 10.000 a 7.000 años de antigüedad. Entonces estos descubrimientos hicieron posible establecer una secuencia cultural para las primeras ocupaciones altoandinas.

Las manifestaciones rupestres de Oqhoruni, también conocido como Jakajlluni, está ubicada hacia al suroeste del centro poblado de Isivilla. Este, políticamente pertenece al distrito de Corani, provincia de Carabaya, departamento de Puno, a $15 \mathrm{~km}$ en la parte este del capital de distrito a una altura de $4,320 \mathrm{msnm}$., está situado a una latitud de $13^{\circ} 50^{\prime} 26^{\prime \prime}$ y a una longitud de $70^{\circ} 30^{\prime} 27$ ". La naturaleza topográfica del lugar está constituida por una serie de afloramientos de toba volcánica que semejan bosques de rocas. En la zona hay numerosos cobertizos y reparos, algunos pequeños y otros grandes. Precisamente uno de esos cobertizos es el que alberga el conjunto de pinturas halladas, donde sobresalen representaciones de animales, figuras humanas y geométricas. El sitio está a $4402 \mathrm{msnm}$ que antiguamente debió ser un corredor de lava se contempla un paisaje entrañablemente telúrico puneño, hacia este se encuentran los nevados perpetuos de Allincapac y Chichicapac y hacia nor-oeste el nevado de Quelcaya, cerca al nudo de Vilcanota, de este nevado se forma el río de Corani.

Actualmente, el sitio arqueológico de Oqhoruni o Jakajlluni, exactamente se encuentra a 2 $\mathrm{km}$ del mismo centro poblado, es decir para trasladarse al sitio se demora de 10 a 15 minutos en unidades vehiculares y 40 a 45 minutos caminado de herradura tomando el camino con dirección hacia la comunidad de Chacaconiza. De manera que para llegar a la comunidad de Isivilla hay que tomar la carretera transoceánica que une los puertos del Perú con los puertos 
del atlántico del Brasil. De Puno a Macusani, capital de la provincia de Carabaya, en un recorrido de 4 horas existen $231.80 \mathrm{~km}$ de carretera asfaltada. Luego se continua de Macusani a Ollachea por la carretera afirmada en muy buenas condiciones y en el kilómetro 40 se toma el desvío hacia la izquierda rumbo a Isivilla, a través de una carretera trocha carrozable que conduce al propio sitio.

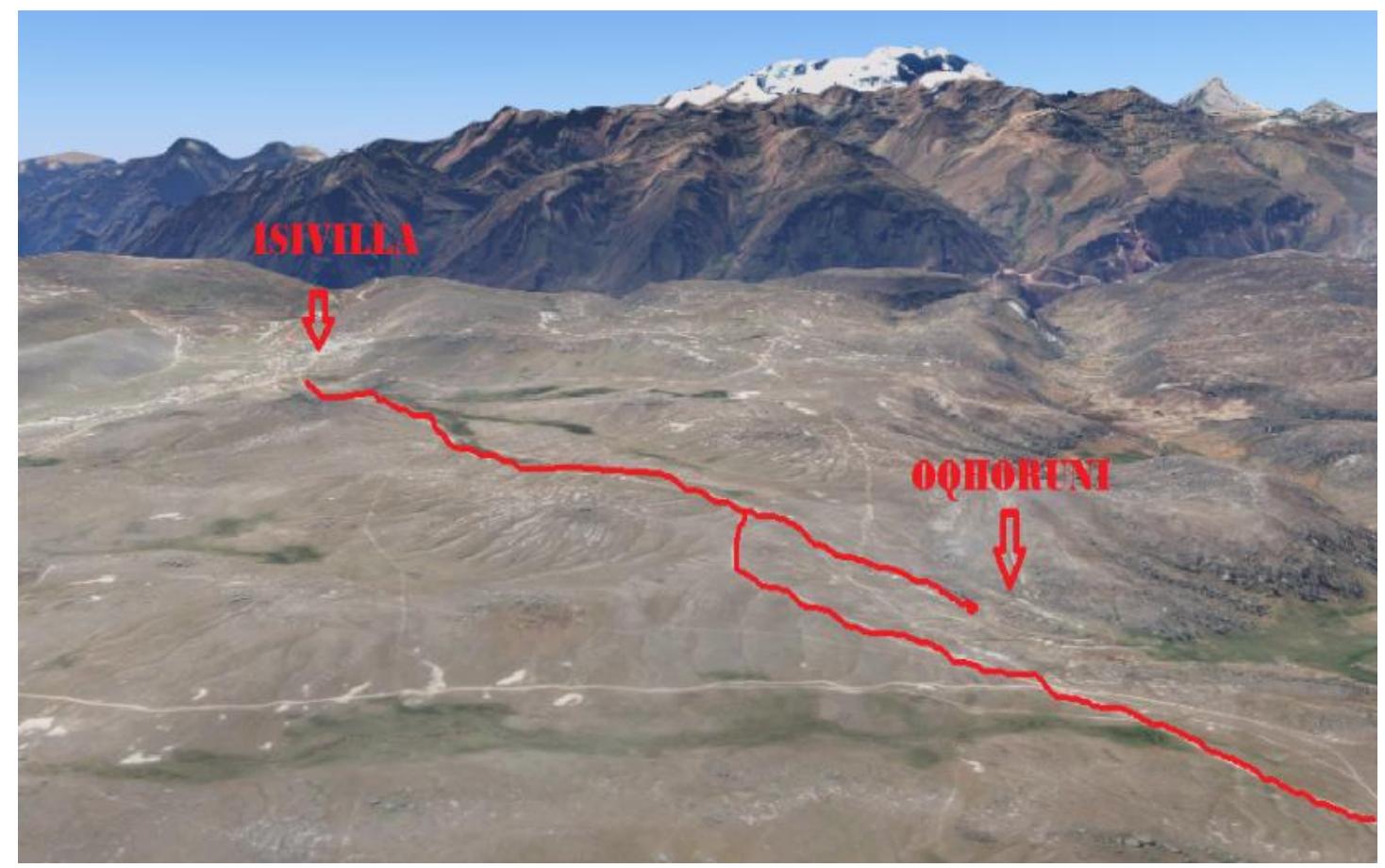

Figura 1: Acceso al sitio arqueológico de Oqhoruni.

En esas radiactivas, el proceso de investigación se realizó en dos fases de trabajo, la primera consistió en la revisión de fuentes bibliográficos existentes relacionados con el tema de estudio (Huanca-Arohuanca, 2021a; 2021b; 2022a; 2022b; Huanca-Arohuanca \& Morán, 2021; Huanca-Arohuanca \& Pilco, 2021a; 2021b) y en la segunda se realizó la salida de campo para las observaciones en profundidad acompañado de una guía, esto permitió conocer de más cerca los significados de las pinturas rupestres de dicha zona, para ello se ha contado con materiales de apoyo, entre los más relevantes, el cuaderno de campo y una cámara filmadora. Las estrategias para recolección de datos se planificaron de acuerdo a un procedimiento, a partir de un cronograma dividido en tiempo y espacio, de tal manera que los procesos de la investigación respondiesen de manera objetiva a las preguntas de investigación (CanazaChoque, 2020a; 202ob; 2020c; 2020d; 2021a; 2021b; 2021c; Canaza-Choque et al., 2021).

Tabla 1: Población y muestra de estudio de la investigación.

\begin{tabular}{ccccll}
\hline Provincia & Distrito & $\begin{array}{c}\text { Centro } \\
\text { poblado }\end{array}$ & Lugar & Cuevas & Paneles \\
\hline \multirow{2}{*}{ Carabaya } & \multirow{2}{*}{ Corani } & Isivilla & & Abrigo rocoso 1 & \\
& & & Abrigo rocoso 2 & \\
& & & & Abrigo rocoso 3 & 3a \\
& & & & Abrigo rocoso 4 & $4 \mathrm{a}$ \\
\hline
\end{tabular}

Revista Revoluciones -40-Vol. 3, No 6 (2021), pp. 37-52

Esta obra está bajo una licencia internacional Creative Commons Atribución 4.o. 
Abrigo rocoso 5

Abrigo rocoso 6

\section{RESULTADOS}

\section{Primeras formaciones de la comunidad de Isivilla}

Sus orígenes y formación se remota a la siguiente leyenda, en Usicayos vivía un cacique Inca y su hijo quien se enamoró de la hija de Pachapuma, enamorado el joven quien se fugó del lado de sus padres y en persecución quien llegó hasta patapampa (Macusani) dejando el lugar explanado. En la búsqueda de la hija de Pachapuma llegó a pacaje donde se dice que los pobladores de esa zona escondieron a la hija de Pachapuma, entonces desesperado el hijo de cacique Inca prosiguió con la búsqueda hasta llegar al lugar de phaspaya que está a $8 \mathrm{~km}$ al norte del actual Isivilla, donde se enfrentó con los trabajadores de las minas de huanacaire y k'achiria quien antes de ser capturado se desfogó con hondazos de encima de una roca donde había quedado una huella de su pie que existe hasta la actualidad. Según versiones de los pobladores de Isivilla al ver la huella en la roca denominaron al lugar "ese huella" y posteriormente los pobladores de la zona dieron sentido a la palabra con la denominación de Isivilla.

\section{Características de las figuras iconográficas de las manifestaciones pictográficas de Oqhoruni}

En los momentos iniciales del formativo temprano, se articulan ciertos cambios en cuanto a representación de motivos y escenas, posiblemente sufren cambios drásticos a fines de esta época (Aroquipa \& Almonte, 2015). Al respecto, Mamani (2017) dice en un primer momento el arte rupestre paleolítico se consideró como puramente ornamental, carente de significados más complejos. Este punto de vista se apoyaba en el arte mueble conocido hasta entonces. Pero los avances en el conocimiento de esa época, así como los descubrimientos que se iban haciendo, pusieron de manifiesto que había un complejo, aunque indescifrable nexo entre los objetos representados y su localización. Se pintaba un limitado número de especies; con frecuencia las pinturas, dibujos y grabados se encuentran en los lugares más inaccesibles de las cuevas; hay asociaciones y signos enigmáticos, figuras intencionadamente incompletas o ambiguas, y cuevas decoradas que aparentemente fueron habitadas.

Para Ortiz (2013) en cuanto respecta a los colores utilizados en el arte rupestre de Tantamaco e Isivilla. Prevalece el color rojo oscuro, le sigue el blanco, rosado, amarillo pardo, anaranjado y muy escasamente en color negro. Al parecer los pintores de esta zona, emplearon la técnica de la policromía como recurso para lograr un mayor efecto estético, así se puede observar que existen figuras humanas de diferentes colores. En las escenas descritas en algunas se muestran a los camélidos que están representados en rebaños, dispuestos en grupos desordenados o solitarios, conformando escenas en las cuales corren a distintas direcciones 
perseguidas por los cazadores, casi siempre encerrados o flanqueados en cercos, se visualiza también animales abatidos con dardos clavados en el lomo. Es frecuente también la representación de crías acompañadas por sus madres en posición de huida escapando de sus captores, en la mayoría de los casos existe un patrón estilístico básico, que es la representación de animales en perfil.

Para Hostnig (2007) la gran mayoría de las figuras humanas de Tantamaco e Isivilla representan a cazadores o a sus ayudantes en las faenas de caza. Están presentes en todos los paneles más antiguos, pero muestran diferentes grados de abstracción y de detalles. Las más frecuentes son aquellas que forman parte de las escenas de caza y están premunidas de un haz de dardos. Algunas están representadas con un brazo en alto agarrando una lanza dardos o estólica en brazo elevado. El haz contiene entre tres y cinco dardos que el cazador carga en forma transversal a la altura de la cintura o cadera, manteniendo así libre uno de los brazos que necesita para el empleo de la estólica. EI otro brazo esta doblado hacia la cadera o falta por completo. A estas figuras antropomorfas peculiares, las he bautizado con el nombre de cazadores portadardos.

Otros cazadores van armados de porras o llevan consigo solo un dardo o una lanza. Es relativamente fácil reconocer la estólica con gancho como instrumento para la propulsión del os dardos, y la porra (o mazo), posiblemente utilizada para rematar las presas acorraladas entre los cercos. Están ausentes el arco y la flecha en las representaciones y tampoco se encontraron en la superficie de los aleros puntas de proyectil atribuibles a flechas. Los primeros cazadores hombres primitivos fabricaban escasos instrumentos lanzas y dardos. La vida cotidiana estaba totalmente sujeta a las actividades de subsistencia. Bajo condiciones extremas de clima y geografía, en un ambiente hostil, donde sobrevivir y alimentarse podían ser desafíos muy altos. Por tanto, era necesario enfrascarse en la caza y que esta fuera exitosa con toda probabilidad.

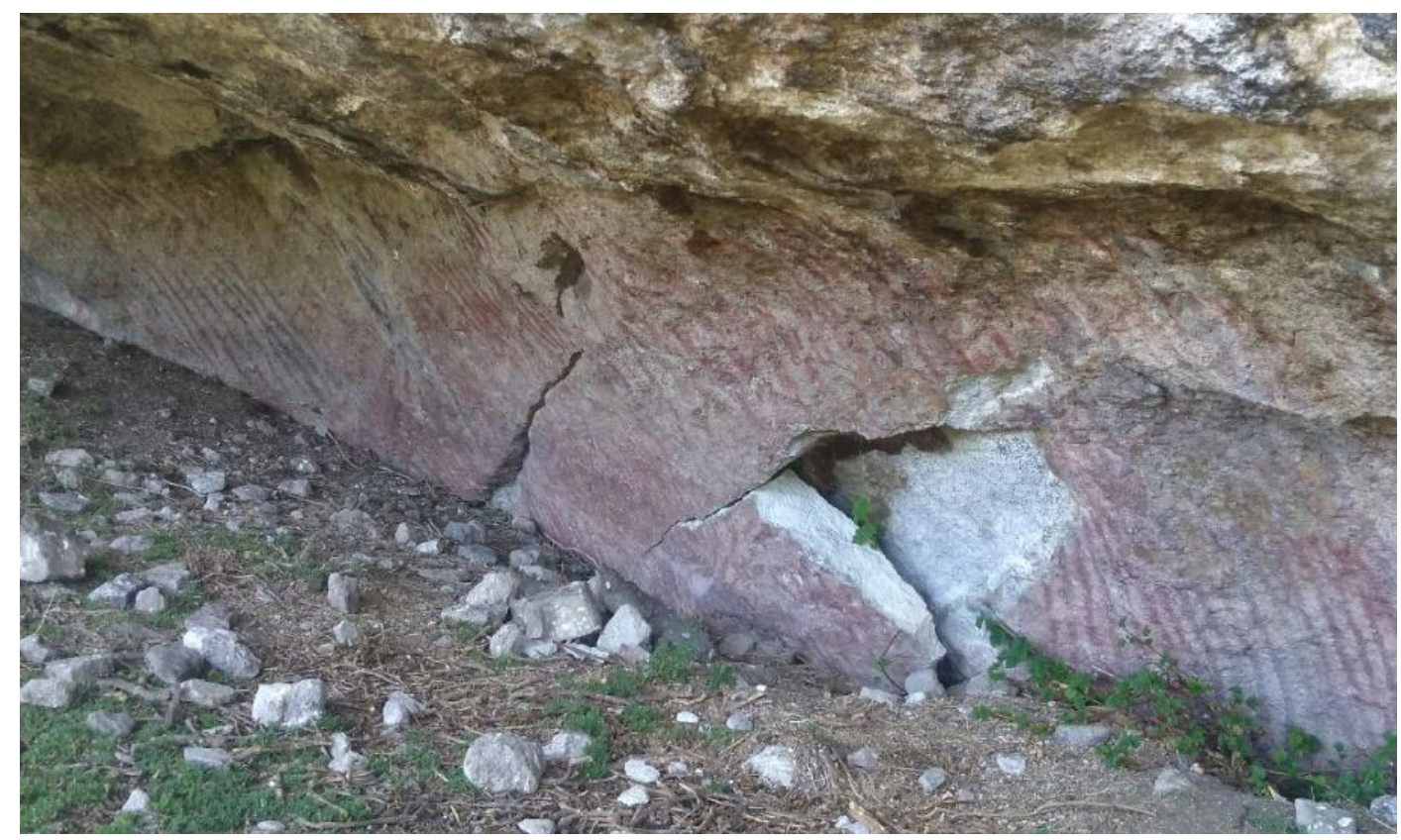

Figura 2: Líneas verticales en toda la pared del alero rocoso.

Revista Revoluciones -42- Vol. 3, No 6 (2021), pp. 37-52 Esta obra está bajo una licencia internacional Creative Commons Atribución 4.0.

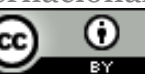


Este primer alero rocoso se ubica en la parte inferior del cerro Oqhoruni mostrándose hacia lado Este. En esta cueva se presenta solamente un panel y en toda su pared de un risco, prácticamente en su totalidad del alero rocoso se aprecian las manifestaciones pictográficas, líneas paralelas verticales en su mayoría líneas rectas de distintos tamaños, el más largo mide de $2.5 \mathrm{~m}$ y la pequeña $5 \mathrm{~cm}$, hechas en una distancia de 8 a $10 \mathrm{~cm}$, sin excepción de alguna de color rojo oscuro. Esto es una clara evidencia de que los hombres primitivos han estado presente en este abrigo rocoso, ahora es cierto que nos cuesta interpretar el significado, pero el más acertado es asociarlo a un sistema de contabilidad, control y registro de camélidos que cazaban a diario o inter diario. Por lo tanto, las líneas que se observan han sido uno de los medios utilizados para hacer visible su pensamiento. Desde los más remotos signos en las paredes de las cuevas o en piedras sueltas, hasta la aparición de los primeros alfabetos pasaron miles de años y así el hombre, en el devenir del tiempo fue imponiendo a las líneas nuevas funciones. En cada etapa de la evolución del hombre, las líneas se han mantenido como una de las más constantes servidoras del hombre.

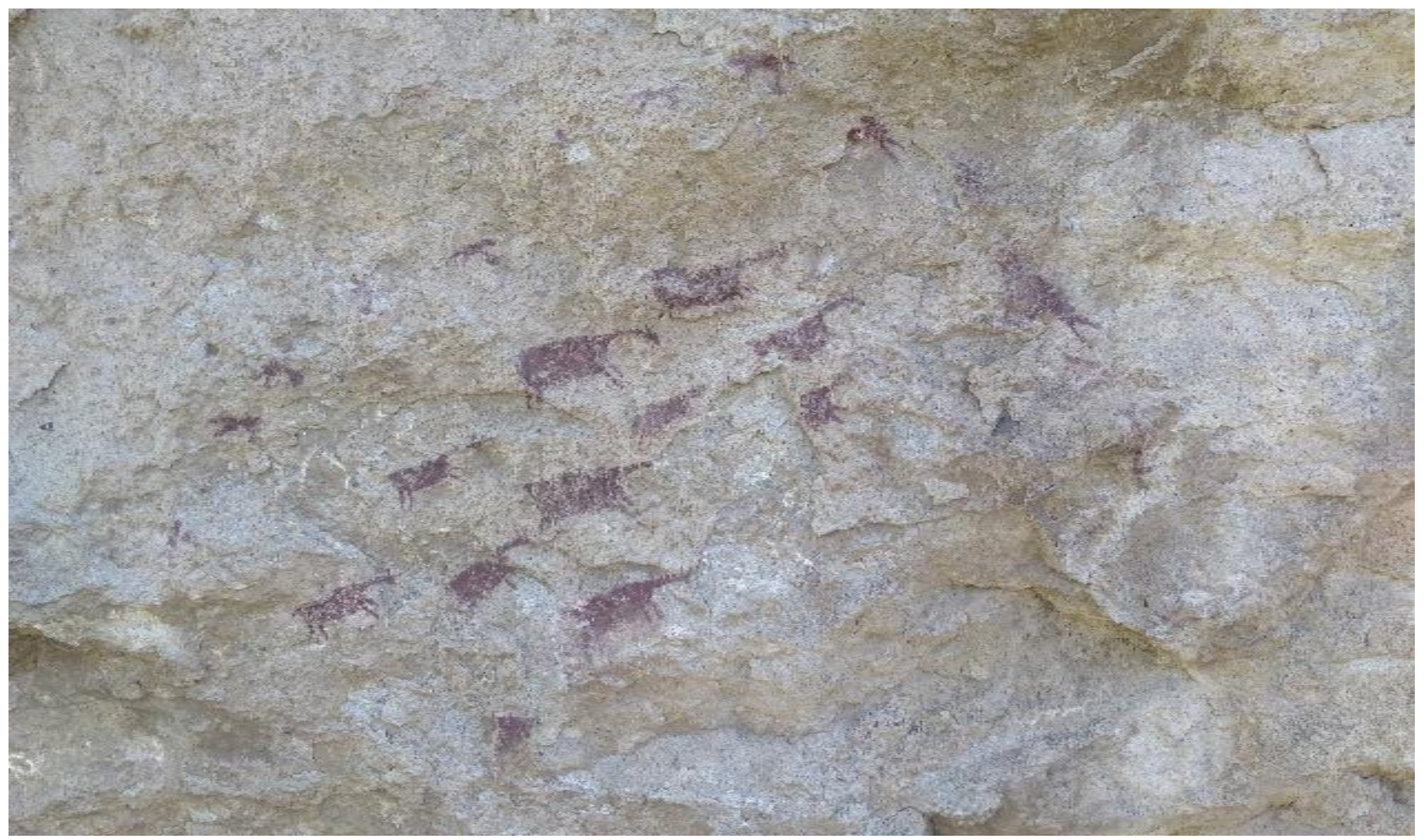

Figura 3: Hombres cercando a un grupo de animales.

Se ubica al frente del primer alero a un aproximado de 50 metros, el alero rocoso se muestra hacia lado Oeste. A diferencia del primer alero, en esta se aprecia figuras antropomorfas y zoomorfas, pintados de color rojo oscuro haciendo un total de 11 camélidos de patas y cuellos delgados y 06 hombres respectivamente armados con lanzas y dardos en la mano. Es evidente que se trata de una escena de caza por la representación de conjunto de auquénidos que están siendo rodeados por un grupo de hombres. Entonces estos auquénidos que se observan en la 
imagen tienen una relación con satisfacerlas las necesidades básicas de los antiguos pobladores de la zona.

Entonces no hay la menor duda de que los hombres primitivos que estuvieron en estos abrigos rocosos de Oqhoruni, tuvieron a la caza de animales como una de sus actividades más importantes para lograr su subsistencia en los frecuentes movimientos erráticos por estos sitios. Por eso ellos plasmaron hechos reales que los rodeaban en cada una de las manifestaciones.

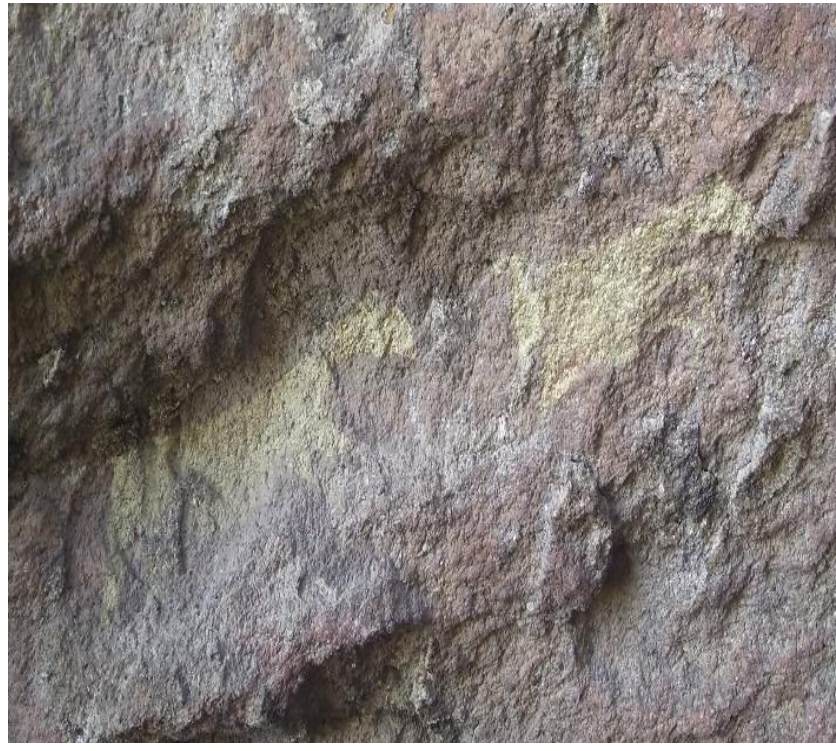

Figura 4: Felino cazando a un camélido

Este se ubica en el mismo cerro de Oqhoruni a un aproximado de 20 metros del alero rocoso 02, mostrándose hacia lado Sur. En el abrigo rocoso 3 se presenta dos paneles y está constituida por un pequeño abrigo rocoso que mide $4.40 \mathrm{~m}$. de altura y 80 a $90 \mathrm{~cm}$ de profundidad desde la boca hasta la pared. Solo en el lado izquierdo se puede apreciar las manifestaciones.

En este abrigo rocoso de Oqhoruni sea observado una escena excepcional, en la cual un puma pisa los talones de un camélido, se desplaza de la izquierda hacia la derecha y está representado en posición de corriendo detrás del camélido, quizás el felino ha logrado aislar de la tropilla. Las características del felino, tiene una cola larga volteada hacia el dorso, las orejas redondeadas y con dos extremidades sin indicación de zarpas, de $7 \mathrm{~cm}$ de largo de color amarillo. Este animal vive en zonas en las que se pueden mezclar fácilmente con el entorno, y en la actualidad existen y viven en el sector de Oqhoruni, su habitad natural está en las áreas alto andinas al igual que de los camélidos, donde fácilmente pueden moverse y buscar comida. 


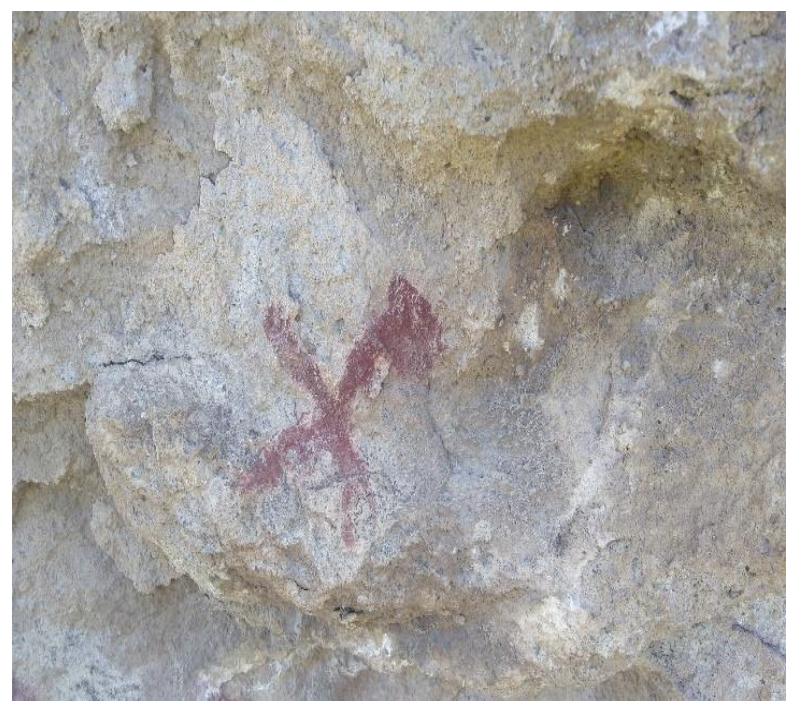

Figura 5: Hombre armado con un especie de mazo.

Panel 02 del abrigo rocoso 03: En la parte inferior al lado izquierdo de la pared del abrigo rocoso se observa una figura antropomorfa altamente esquematizada, de color rojo oscuro y de dimensiones diminutas, de $3 \mathrm{~cm}$ de altura. Cabeza ovalada sin cuello, torso grueso, piernas rígidas separadas, dibujada en movimiento, los brazos extendidos, uno de ellos frecuentemente flexionado hacia arriba. Porta en una o en ambas manos un objeto alargado que sugiere ser un mazo.

Entonces el sitio epónimo de esta antigua tradición de cazadores andinos en diferentes sitios. Busto (1975) afirma que atraídos por la caza de auquénidos los hombres de la sierra empuñaron sus garrotes y cruzaron áreas alto andinas. Haciendo sus garrotes y cansado de perseguir a los guanacos, encontraron un día, una gran cueva y decidieron descansar, acaso también podían defenderse del frio, porque encendieron hoguera como lo atestiguan las cenizas. Lo cierto que fue que este descanso resulto muy prolongado, tiempo indefinido a lo largo de lo cual el brujo del grupo, a la luz de las antorchas, pinto escenas relacionadas a la caza. 


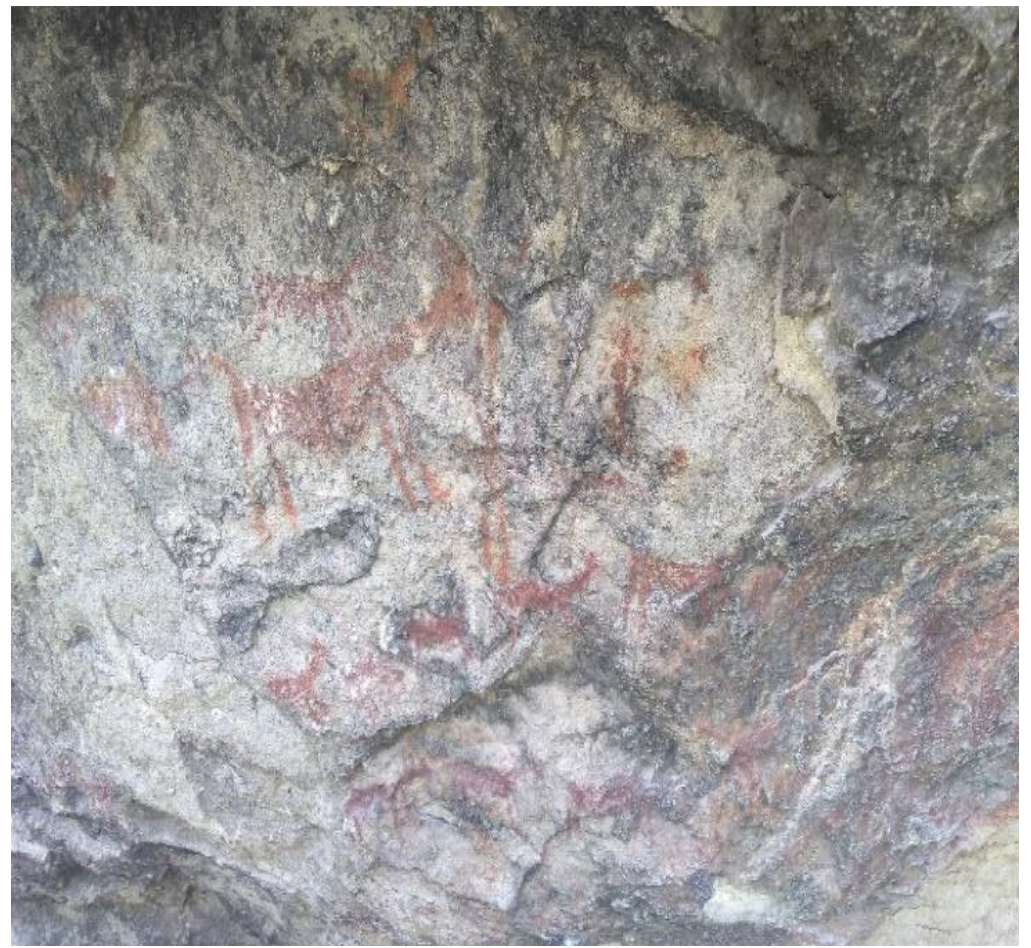

Figura 6: Siervos corriendo perseguidos por cazadores armados.

Se ubica a 7 metros del alero rocoso 3, donde se muestra las imágenes en la parte superior del lado derecho del abrigo rocoso que también se muestra hacia lado Sur. Aquí se precisa una manada de ciervos perseguidos por un grupo de cazadores plenamente armados con palos, los animales corren hacia un cerco y se encuentran rodeados por cazadores armados de mazos. Estilísticamente tienen similitud con los camélidos. En este panel, una tropilla de ciervos de color anaranjado, más similares a los camélidos por su mayor exactitud anatómica, con dos o más cuernos saliendo de la cabeza, es perseguida por cazadores armados de dardos. Estos animales se entremezclan en su afán de escapar de sus perseguidores armados con dardos. 


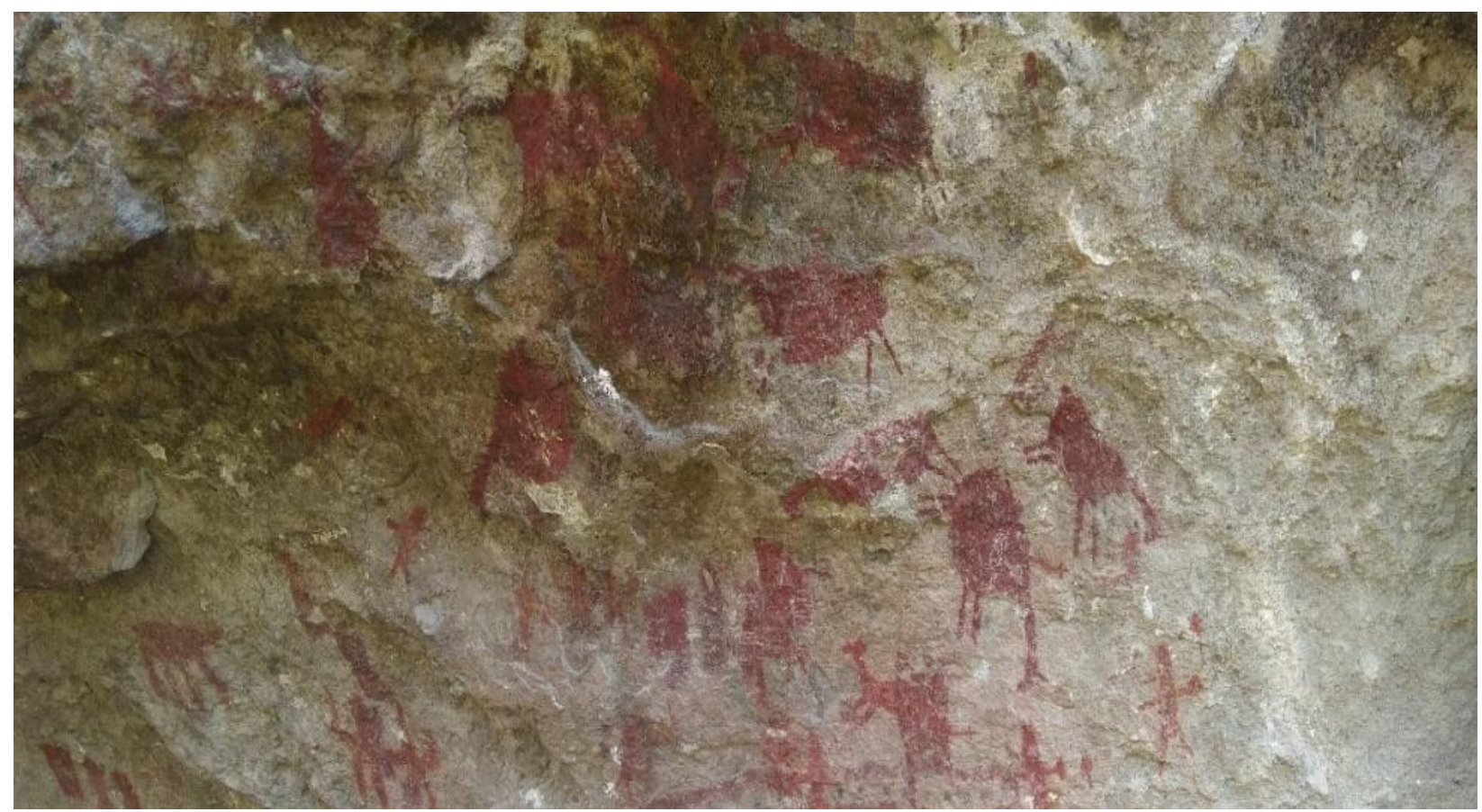

Figura 7: Animales siendo abarrotados por un grupo de hombres.

En la parte derecha al inferior se observa unos 13 camélidos de cuellos y patas delgadas que están siendo abarrotados por un grupo de hombres armados. Escena de caza dramática de camélidos fielmente pintados muestran diversas actitudes, la mayoría están heridos donde algunos exhiben dardos incrustados en el dorso, pintado de color rojo, verde, negro y anaranjado. El proceso de domesticación de los camélidos sudamericanos habría comenzado hace 6000 - 5000 años, donde los primeros hombres sean encontrado con el guanaco, llama y la alpaca, posteriormente aplicando estrategias de crianza y someterlas para dar pie a sus contrapartes domésticas. De esta manera el poblador aseguró un medio de carga y, a la vez, una fuente de carne, cueros, pieles; pero lo más importante es que bajo esas rigurosas condiciones se estableció un sólido vínculo del hombre con animal.

Los cérvidos es el segundo animal más frecuente en los paneles, muy probablemente la taruca, que tiene su hábitat preferido entre los 3300 y $5000 \mathrm{msnm}$. En las pinturas rupestres la observamos formando pequeñas manadas, atrapadas en corrales y huyendo de cazadores visibles o imaginarios. Se puede distinguir dos patrones estilísticos en la representación de este ungulado: uno de mayor exactitud anatómica, y el otro de cuerpo voluminoso y angular, pero de cuello grueso y corto.

\section{Importancia y conservación de las manifestaciones rupestres.}

Son pocos los paneles de pintura rupestre en la zona de estudio que se encuentran completamente intactos. La mayoría de ellos demuestra diferentes grados de deterioro por causas principalmente naturales y en mayor medida por influencia antrópica. El mal estado de muchos paneles se debe a la propensión de los soportes (toba volcánica) a la erosión. Los 
fenómenos termodinámicos (cambio brusco de temperaturas e insolación) provocan la exfoliación de las rocas con sus efectos devastadores sobre las pinturas.

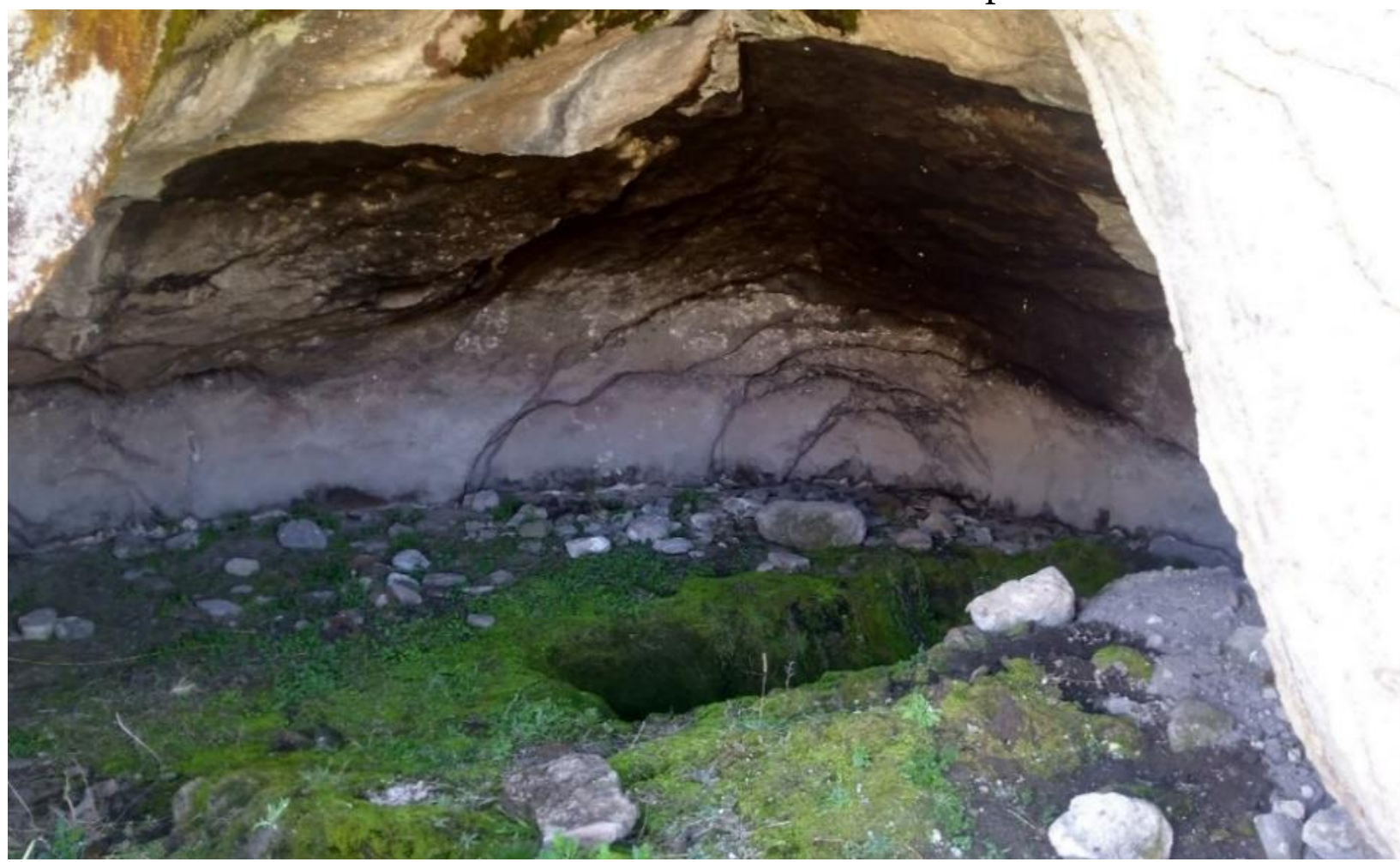

Figura 8: Cueva escarbado por los huaqueros.

El desprendimiento de la cutícula o de placas enteras ha dañado severamente un número elevado de sitios y hay algunos, donde los paneles han desaparecido casi por completo quedando solo fragmentos pequeños de figuras aisladas o escenas. En lugares expuestos a los fuertes vientos vespertinos, las paredes de los abrigos y con ello las pinturas rupestres se encuentran impregnadas de polvo y arena, dificultando o imposibilitando el reconocimiento de determinadas figuras o escenas.

También han sido afectados varios paneles por el afloramiento de sales y, en el caso de paredones de escaso cobertizo, por el escurrimiento de agua con la consiguiente formación de hongos que a veces cubren con manchas negras áreas importantes de algunos paneles haciendo difícilmente discernibles las figuras subyacentes.

El hombre actual participa directa e indirectamente en la destrucción de sitios. Al utilizar las cuevas o abrigos con arte rupestre para fines de vivienda temporal en las épocas de siembra y cosecha de tubérculos, parte de los paneles fueron cubiertos con capas gruesas de hollín de los fogones, dificultando el reconocimiento de las pinturas o petroglifos o haciéndolos prácticamente irreconocibles. Muchos de los abrigos más grandes han sido habilitados como corral de animales lo que ha dañado las pinturas rupestres en la base de las paredes al rasparse los animales contra ellas y por la acumulación de estiércol que puede alcanzar de 10 a $50 \mathrm{cms}$ de profundidad. Y, por último, aunque todavía en forma incipiente, algunos sitios han sufrido el impacto de actos vandálicos por parte de jóvenes del lugar, con la imitación y 
el agregado de figuras, la superposición de grafitis empleando carbón, tiza o piedras de color diverso.

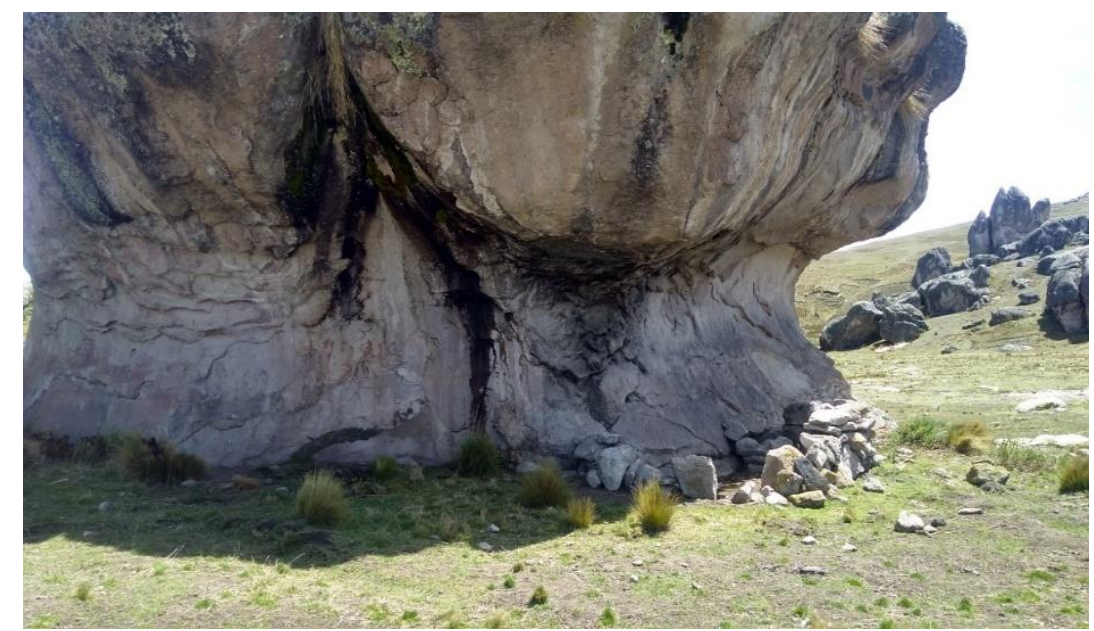

Figura 9: Abrigo rocoso habitado por los hombres actuales de Isivilla.

Todo abrigo creado por la naturaleza fue utilizado donde estuvo los primeros hombres ritualmente y eficazmente para plasmar sobre sus paredes las manifestaciones rupestres; es por ello que en la actualidad podemos observar por la cubierta lítica ha generado sombra y ha protegido de la luz, viento y la lluvia. Las manifestaciones rupestres, que aparece sobre la faz de la tierra hace aproximadamente 40.000 años, es una de las manifestaciones artísticas más antiguas de la humanidad, se basa principalmente en la elaboración de dibujos o imágenes grabadas en superficies rocosas, se destacan dos tipos principalmente: las pictografías y los petroglifos.

El hombre se refugiaba en las cuevas para protegerse principalmente del terrible frio y también se puede decir del ataque de algunos animales. El hombre vive en estado nómade pasando a ser semi-sedentarios, ya que el frio y los peligros que le acechan, esto hace u obliga a permanecer en la caverna. La prolongada permanencia en las cuevas transforma al hombre en un ser reflexivo. Las pinturas, por ello, han sido ejecutadas despaciosamente, y a esto se debe el sentido de perfección que las anima. Las pinturas de los abrigos rocosos son verdaderas obras muestras del arte.

En las pictografías utilizaban una variada gama de colores de rojos, ocres, anaranjados y amarillos, además de estos el negro y blanco. Principalmente encontramos estas pinturas sobre las superficies rocosas, en estas pinturas utilizan sustancias minerales y vegetales de las cuales podemos nombrar algunas para un mejor entendimiento de esto, en las minerales encontramos el carbón y la arcilla, en los animales sangre y huevos y en las vegetales grasas y colorante. Para pintar se usó el pincel de cerdas de animal, pero a veces los propios dedos humanos. Con frecuencia lo primero que se hace es el perfil mediante una línea grabada. En mayor proporción en las manifestaciones pictográficas predomina el color rojo, pero en una gama muy amplia, combinándose con ocre, procedente de algunos minerales y vegetales. Como elemento disolvente se empleaba la grasa de animal, en ocasiones mezclada con sangre. 
La observación de las manifestaciones rupestres como rastros de la conducta que tuvieron los hombres primitivos; tal como se observa en los paneles como la caza a los animales, principalmente a los camélidos y otros animales que en la actualidad existen. En cuanto a los petroglifos se encuentran en superficies rocosas, pero estos son imágenes grabadas en estas superficies, utilizaban elementos como punteros de piedra o elementos fuertes con las que pudieran realizar estos grabados. Este estilo de arte fue realizado como un lenguaje de los primeros hombres, para datar sus rituales y que las personas que llegaran a ese lugar supieran de los peligros o cosas buenas que podrían encontrar en ese ambiente, otras veces era para datar sus rituales o simplemente como una expresión puramente estética. Entonces las manifestaciones rupestres que se ha encontrado en diferentes partes de nuestro departamento y el país, ya que este tipo de arte se expandieron y fue de suma importancia como un lenguaje de comunicación en ese entonces.

\section{DISCUSIÓN}

El presente trabajo de investigación ha sido elaborado en base a 4 sitios rupestres ubicados en el sector de Oqhoruni de la comunidad de Isivilla. En la visita al sitio, el investigador, ha podido registrar el sitio y las figuras iconográficas para su descripción. Si bien los sitios registrados pueden considerarse representativos del arte rupestre de Isivilla. Las manifestaciones pictográficas de Oqhoruni han sido producidas en el arcaico tardío. En las o4 cuevas en los que se pueden observar, imágenes de camélidos y hombres armados con dardos en la mano sin duda del periodo arcaico, excepto las figuras geométricas, de la cueva o1 de líneas paralelas con algunos detalles. En base al análisis iconográfico y de superposiciones realizados se pueden observar las manifestaciones pictográficas tardías. En cuanto escenas en los abrigos rocosos de Oqhoruni se encuentra las figuras iconográficas antropomorfas, zoomorfas y geométricas.

Los resultados que sostiene el investigador Hostnig (2007, 2010) en cuanto a las pinturas rupestres de Isivilla guardan relación. Hosting (2010) el arte rupestre de Isivilla no sólo evidencia que la caza de camélidos silvestres, en los milenios anteriores a su domesticación, representó la principal actividad económica de los primeros pobladores, sino que nos revela también detalles interesantes sobre los métodos de caza, las armas empleadas, la indumentaria de los cazadores, posibles rituales vinculados con la caza, así como sobre la capacidad de observación y el gran sentido estético de los autores de las pinturas. Mamani (2014) en su tesis, en sus resultados sobre las características iconográficas de las pinturas rupestres de la comunidad de Tantamaco se describe lo siguiente: Sobresalen en su mayoría las iconografías muestran la alta concentración de escenas de caza, con presencia de hombres portando instrumentos de caza, como dardos y ondas, trampa en forma de escalinatas, hombres agarrados de las manos, algunos conocidos como portando dardos en fila.

Ello es lo que se halla en este estudio; pero, en lo que no concuerda es con su título de la investigación que señala: Interpretación y esto casi no se evidencia en sus resultados, en lo 
que acabamos citar es una descripción genérica. $Y$ en lo respecta a la relación sobre las manifestaciones pictográficas de Isivilla-Tantamaco, Mamani (2014) y Hostnig (2007) señalan en sus respectivos estudios que sobresalen las figuras geométricas por sus respectivos decorativos, por la utilización de varios colores para pintado como rojo, ocre, blanco, cada una en sus respectivas tonalidades, y también hombres en escenas de caza en muchos paneles potando armas como ondas y dardos.

Mamani (2017) en su tesis titulada "Descripción e interpretación de las artes rupestres de Pisacoma, en las cuevas y abrigos Puno-2015” egresado de la Universidad Nacional del Altiplano, en el año 2016. En sus resultados de la presente investigación dice: Las imágenes que presentan las pinturas rupestres de Pisacoma tienen variedad de representaciones una de las cuales se encuentra en esta comunidad de Quimsuyo. En esta cueva se representó mantas o mantones ceremoniales. En donde se deduce que fue por el respeto a las deidades. En donde ellos sintieron esa necesidad a modo de respeto con sus dioses representar infinidad de modelos de mantas ceremoniales.

\section{CONCLUSIONES}

Las manifestaciones pictográficas de Oqhoruni, están presentados en las paredes de los abrigos rocosos en figuras antropomorfas, zoomorfas y geométricas en diferentes posiciones, tamaños y colores. Principalmente en escenas como la caza, chacu y caicu, actividades que realizaban para la sobrevivencia. Las manifestaciones pictográficas de los abrigos rocosos de Oqhoruni de la comunidad de Isivilla se encuentran en distrito de Corani, provincia de Carabaya del departamento de Puno. Límite con la comunidad de Tantamaco del distrito de Macusani, que también cuenta con cuevas y paneles con imágenes pictográficas como muestra y prueba de su existencia como los primeros hombres y pobladores del altiplano.

Las manifestaciones rupestres de Oqhoruni de la comunidad de Isivilla corresponde periodo lítico por la presencia de figuras antropomorfas y zoomorfas en escenas de caza, propios de este periodo de hace 10.000 a 7.000 años de antigüedad. En las escenas que más sobresale casi en todos los paneles en excepción del abrigo rocoso $\mathrm{N}^{\circ} \mathrm{O} 1$ son figuras antropomorfas de $8 \mathrm{~cm}$ a $1 \mathrm{~cm}$ de color rojo, rojo oscuro y anaranjado, llevando lanzas y dardos en la mano. Figuras zoomorfas como guanacos, camélidas estilizadas que representan cuerpos largos y anchos, cuellos y patas delgadas, ciervos con cachos en la cabeza, felino como el puma, pintadas en diferentes tonalidades.

Las manifestaciones rupestres son riquezas culturales de nuestra región, por estos dibujos que hoy en día existen en diferentes sitios sabemos algo sobre la actividad rutinaria que realizaban los primeros pobladores; por ello, es muy importante dar la importancia y la conservación, porque en estos últimos años se encuentran como uno de los vestigios más vulnerables de nuestro patrimonio cultural.

\section{REFERENCIAS BIBLIOGRÁFICAS}

Revista Revoluciones -51- Vol. 3, № 6 (2021), pp. 37-52

Esta obra está bajo una licencia internacional Creative Commons Atribución 4.0. 
Alanoca, R. (2011). Interpretación mágico religioso de las Pinturas Rupestres de Qelqatani de la comunidad de Chichillapi-Masocruz. UNA - PUNO.

Bernarik, R. (1988). El arte de los comienzos. Revista: El correo de UNESCO, vol. No 48, p. 10.

Canaza-Choque, F. A. (2020a). Educación superior en la cuarentena global: disrupciones y transiciones. Revista Digital de Investigación en Docencia Universitaria, 14(2), 1-10.

Canaza-Choque, F. A. (2020b). La gran estampida. Humanos caminando en la modernidad líquida. Encuentros. Revista de Ciencias Humanas, Teoría Social y Pensamiento Crítico, (12), 127-145.

Canaza-Choque, F. A. (2020c). Mariátegui y la agonía de los dioses. Entre encuentros, presagios y desgracias futuras en el panteón andino. Acta Herediana, 63(2), 135-151.

Canaza-Choque, F. A. (2020d). Desafiar y desactivar el mal. Percepciones y notas sobre un desastre climático global en estudiantes de Educación Secundaria. In Crescendo, 11(3), 221-247.

Canaza-Choque, F. A. (2021a). «Por nuestras muertas». El despertar de un poder y la movilización de Ni Una Menos [NUM] en el Perú de 2016. PURIQ, 3(1), 22-47.

Canaza-Choque, F. A. (2021b). El Perú de Mariátegui: detenidos en el tiempo y el despertar de una era. Horizonte de La Ciencia, 11(20), 45-57.

Canaza-Choque, F. A. (2021c). Pandemia 2020 y el poder del Estado. Daños, impactos y respuestas a zonas desprotegidas en escenarios devastadores. Socialium, 5(1), 56-74.

Canaza-Choque, F. A., Escobar-Mamani, F., \& Huanca-Arohuanca, J. W. (2021). Reconocer a la bestia: Percepción de peligro climático en estudiantes de educación secundaria. Revista de Ciencias Sociales, 27(2), 417-434. https://doi.org/10.31876/rcs.v27i2.35932 Castilla, L. (2010). Historia del arte. Recuperado de http:// arterupestre.com/solidaria.html. Clavel, D. \& Fernández, R. (1984) Iniciación al análisis de textos, España: Teide.

Cortés , M., \& Iglesias, M. (2004). Generalidades sobre metodología de investigación. México: ISBN.

Guffroy, J. Jean, J. (1999). El arte rupestre del antiguo Perú. Madrid-España: IFEA.

Hostnig, R. (2003). Macusani y Corani, Repositorios de Arte Rupestre Milenario en la Cordillera de Carabaya.

Hostnig, R. (2007). El Arte Rupestre de Carabaya-Legado Histórico Cultural de Trascendental Valor en un Paisaje de Áspera Belleza. Puno-Perú: Empresa de generación eléctrica San Gabán.

Hostnig, R. (2012). Carabaya Paisajes y Cultura Milenaria. Municipalidad de Carabaya y el Gobierno de Vorarlberg: Grafica Biblos S.A.C. Lima- Perú.

Huanca-Arohuanca, J. W. (2021a). Narrativas de guerra y resistencia: participación de la mujer austral del Perú en la Guerra del Pacífico. Encuentros. Revista de Ciencias Humanas, Teoría Social y Pensamiento Crítico, 13, 50-59. https://doi.org/http://doi.org/10.5281/zenodo.4395218

Huanca-Arohuanca, J. W. (2021b). Un fantasma recorre el Perú del Bicentenario: lecciones y voluntad popular en las elecciones de 2021. Revista Revoluciones, 3(3), 1-4. https://doi.org/10.35622/j.rr.2021.03.001 
Huanca-Arohuanca, J. W. (2022a). A 200 años de Independencia en el Perú y el papel de la historia contado desde la otredad. PURIQ, 4(1), 140-148. https://doi.org/10.37073/puriq.4.1.216

Huanca-Arohuanca, J. W. (2022b). El estado de la cuestión sobre la participación política en los jóvenes de la Nación Aymara - Perú. Un diálogo teórico desde sus actores. Apuntes Universitarios, 12(1). https://doi.org/10.17162/au.v11i5.914

Huanca-Arohuanca, J. W., \& Morán, D. (2021). De independencias a bicentenarios: balances y perspectivas en tiempos turbulentos. Revista Revoluciones, 3(5), 1-4. https://doi.org/10.35622/j.rr.2021.05.001

Huanca-Arohuanca, J. W., \& Pilco, N. (2021a). Acciones revolucionarias en Ámérica Latina: Puno y el Alto Perú durante el proceso de independencia (1809-1825). Chakiñan. Revista de Ciencias Sociales y Humanidades, 14, 70-83. https://doi.org/10.37135/chk.002.14.05

Huanca-Arohuanca, J. W., \& Pilco, N. (2021b). Transición del virreinato a la República: caleidoscopio sociopolítico-económico del altiplano puneño en la Independencia de Perú (1815-1825). Diálogo Andino, 65, 379-391. http://dialogoandino.cl/wpcontent/uploads/2021/07/28-HUANCA-PILCO-RDA-65.pdf

Lumbreras, L. (1969). Los Orígenes de la Sociedad Andina. Lima.Perú. Editores S.R.L.

Mamani, A. (2017). Descripción e Interpretación de las artes rupestres de las cuevas de Pisacoma. UNA - PUNO.

Mamani, E. (2014). Interpretación simbólica de las pinturas rupestres de la comunidad de Tantamaco. UNAP.

Martínez, D. \& Botiva, Á. (2004). Manual de Arte Rupestre de Cundinamarca. BogotáColombia: (ICANH).

Mosques, S. M. (1988). Análisis de las pinturas rupestres del gran techo de la cueva de Altamira. (Tesis doctoral). Universidad Complútense de Madrid.

Ortiz del Carpio, J. (2013). Didáctica de Historia Regional. Puno-Perú. Primera edición.

Ramos, R. (2002). Santuario rupestre de Isivilla - Puno, Perú. En: Revista Universitaria, $\mathrm{N}^{\circ}$ 10: 75-93. UNAP.

Tapia, F. (1985). Contribución a la Investigación Arqueológica en los valles de Sandia y Carabaya. Puno-Perú: Grupo de Arte Hutaraya.

Yaresi, Y. (2017). Interpretación de las figuras icónicas de las pinturas rupestres del abrigo rocoso de Ituata provincia de Carabaya. UNA-Puno. 